\title{
AN INVESTIGATION OF EFFECTS OF AXLE LOAD AND TRAIN SPEED AT RAIL JOINT USING FINITE ELEMENT METHOD
}

\author{
Prachi Katheriya ${ }^{1}$, Veerendra Kumar ${ }^{2}$, Anshul Choudhary ${ }^{3}$, Raji Nareliya ${ }^{4}$ \\ ${ }^{I}$ Research scholar, Government Engineering College, Jabalpur, M.P., India \\ ${ }^{2}$ Principal, Government Engineering College, Jabalpur, M.P., India \\ ${ }^{3}$ Assistant Professor, Shri Ram Institute of Engineering and Technology, Jabalpur, M.P., India \\ ${ }^{4}$ Assistant Professor, People's College of Research and Technology, People's University, Bhopal, M.P., India
}

\begin{abstract}
The goal of this research is to investigate the effects of axle load and train speed at rail joint. A three-dimensional finite element analysis of a rail/wheel contact is conducted on the rail joint section of track and dynamic load is applied to develop an estimate respective stresses at the section. In Autodesk Inventor, different components of wheel/rail assembly i.e. wheel, rail, joint, bars, nuts, bolts, and washers are created separately then all components are assembled, and create a complete model of wheel/rail assembly. The finite element program ANSYS is used to model the contact analysis. This ANSYS is used to simulate the loading and boundary conditions of the rail and wheel contact for a stress analysis. Material properties are assumed to be same for rail and wheel, and considered to be bilinear kinematic hardening in ANSYS.A 3-D finite element model for element model for wheel/rail rolling contact is developed on the most critical section of rail track i.e., rail joint to calculate elastic-plastic finite element analysis and 3D stress response in the contact region. These models should be accurately calculating the $3 D$ stress response in the contact region. The reason for this study is to investigate possible changes in rail and wheel contact design in order to improve the performance of the rail track. Obtained results indicate that the von mises stresses, the maximum shear stress and the Equivalent elastic strain are increases linearly with increasing axle load and the effect of train speed on above parameters is relatively weak.
\end{abstract}

Keywords: Wheel/Rail, Rail-Joint, Stress, contact-impact, FEA

\section{INTRODUCTION}

The track or Permanent Way is the rail-road on which trains run. The track or Permanent Way is the rail-road on which trains run. It basically consists of parallel rails having a specified distance in between and fastened to sleepers, which are embedded in a layer of ballast of specified thickness spread over the formation. The rail are joined each other by fish plates and bolts and these are fastened to the sleepers by various fittings like keys and spikes etc. the sleepers are spaced at a specified distance and are held in position by embedding in ballast.

Each of the components of track has a basic function to perform. The rails act as girders to transmit the wheel loads of trains to the sleepers. The sleepers hold the rails in proper position and provide a correct gauge with the help of fitting and fastenings and transfer the load to the ballast is placed on level ground known as formation. The sleepers are embedded in ballast, which gives a uniform level surface, provides drainage and transfers the load to a larger area of formation. The formation gives a level surface, where the ballast rests and takes the total load of the track and that of the trains moving on it.

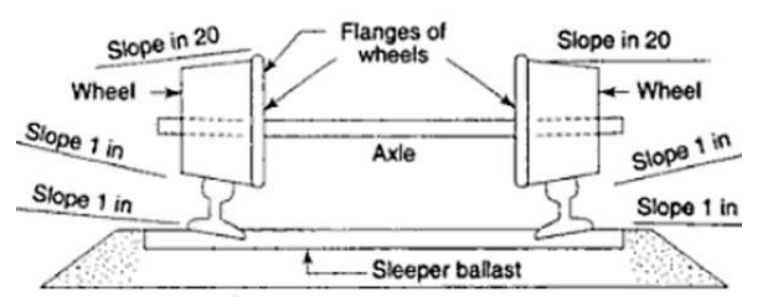

Fig.-1. Assembly of rail wheel axle.

Fig.1 Show assembly of wheel rail contact. Among all the sub-systems and the components that are a part of a railway system, the wheel/rail interface is one of the most delicate, both as regards the performances of the train and as regards its safety. Indeed the problem is complex, due to the fact that damage of the wheel/rail interface depends on many factors and different mechanisms contribute to the deterioration of the contact surfaces. Wear, rolling contact fatigue are the most common types of damage due to the wheel/rail contact.Among all the damage mechanisms, fatigue is one of the most frequent ones. Fatigues causes abrupt fractures in wheel or tread surface material loss. In order to accurately describe the stress state under contact condition, Hertz in Germany gave a more detailed theory to determine the area of contact and the pressure distribution at the surface of contact between the rail and the wheel. As per this theory, the rail and wheel contact is similar to that of two cylinders (the circular wheel and curved head of the head of the rail) with their axes right angles to each other. 
A rail joint is the weakest spots in the railway track. Rail joint are used to connect the ends of two rails horizontally and vertically. The continuity of the railway track is breaks due to the existence of rail gap and difference in the height of the rail heads. Because of the above reasons rail joints are weaker than the rails and subjected to large stress.

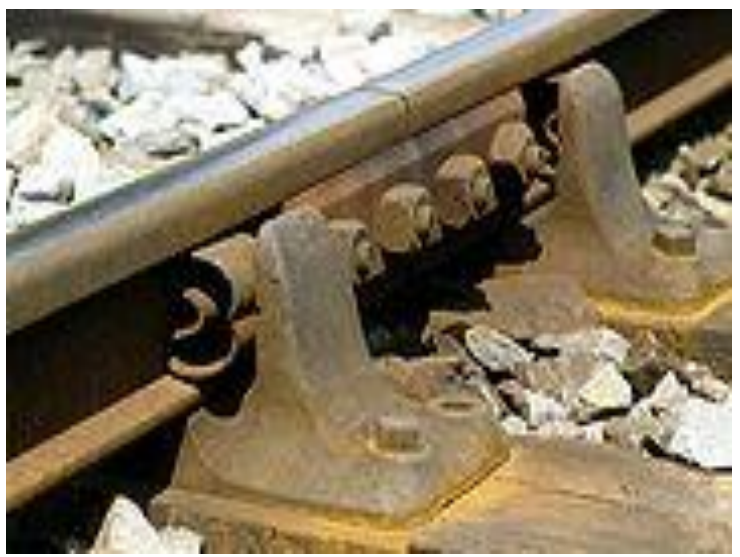

Fig.2Atypical rail joint

\section{FINITE ELEMENT SIMULATION COMPUTATION MODEL}

A 3-D finite element model for element model for wheel/rail rolling contact is developed on the most critical section of rail track i.e., rail joint to calculate elastic-plastic finite element analysis and 3D stress response in the contact region. These models should be accurately calculating the 3D stress response in the contact region. All the finite element models in this task are built using the commercial software ANSYS.

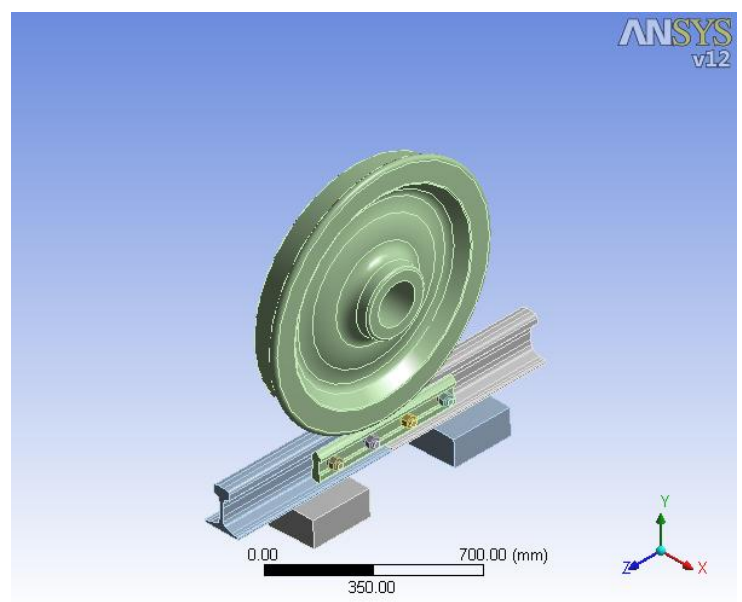

Fig-.3 Finite element modeling of wheel rail set.

In Autodesk Inventor, different components of wheel/rail assembly i.e. wheel, rail, joint, bars, nuts, bolts, and washers are created separately then all components are assembled, and create a complete model of wheel/rail assembly. To calculate the stresses and strain at the rail joint the load and rotational velocity is being applied. After defining material properties and boundary conditions in ansys results are being evaluated and equivalent von mises stresses and equivalent elastic strain are being determined. All the material properties and data are obtained from the Indian railway.

\section{MATERIAL PROPERTIES}

Young's modulus .. 210Gpa

Material density $7820 \mathrm{~kg} / \mathrm{m} 3$

Yield strength $500 \mathrm{Mpa}$

Tangent modulus $4000 \mathrm{Mpa}$

Ultimate tensile strength $880 \mathrm{Mpa}$

Tensile yield strength $\quad 540 \mathrm{Mpa}$

Compressive yield strength $\quad 540 \mathrm{Mpa}$

\section{BOUNDARY CONDITIONS}

In this investigation, we select train speed $\mathrm{V} 0=30,60,70$ $\mathrm{km} / \mathrm{h}$ or $18,36,42 \mathrm{rad} / \mathrm{s}$. and $60 \%$ of axle load or vertically downward loadP0 $=82.8,71.7,110.6 \mathrm{KN}$. UIC 60 rail is mainly used for FE analysis. The wheel and rail in the initial temperature and reference temperature is $22^{\circ} \mathrm{C}$. The diameter of wheel is $918 \mathrm{~mm}$. Friction coefficient is considered as 0.15 , and the material density is $7820 \mathrm{~kg} / \mathrm{m} 3$. Material properties are assumed to be same for rail and wheel, andconsidered to be bilinear kinematic hardening in ANSYS.
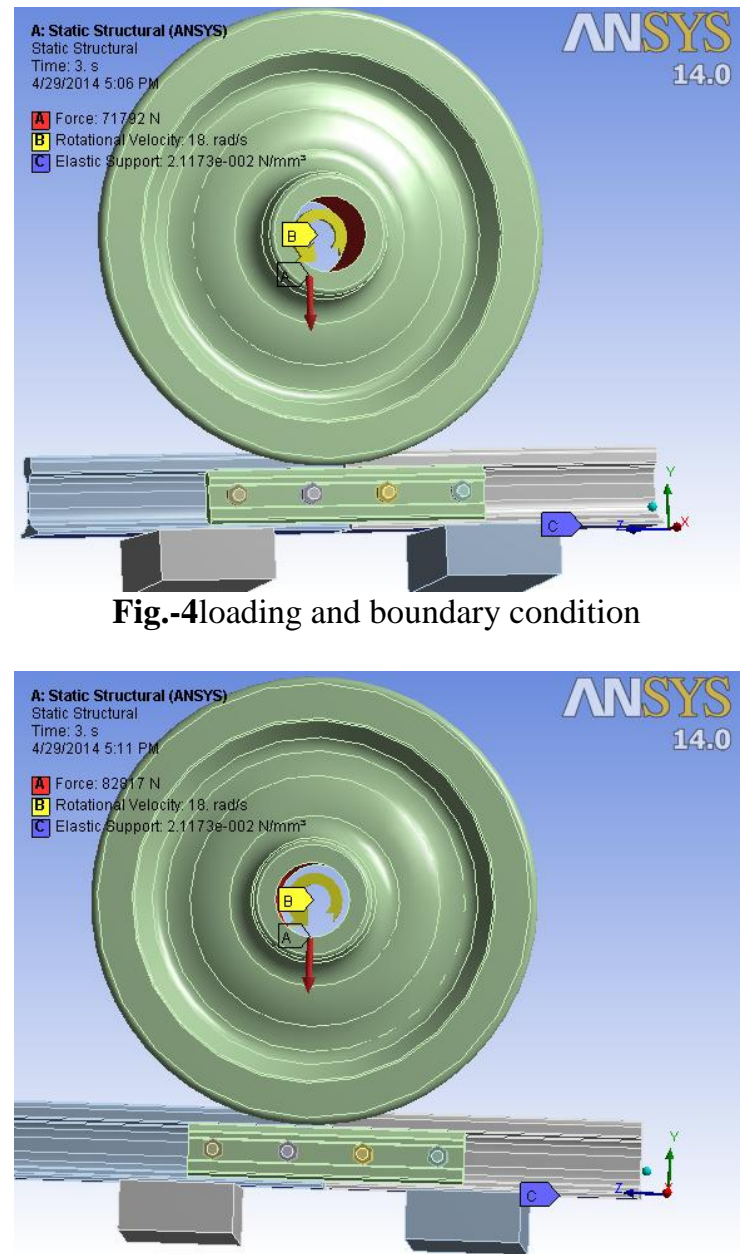

Fig-.5 loading and boundary condition 


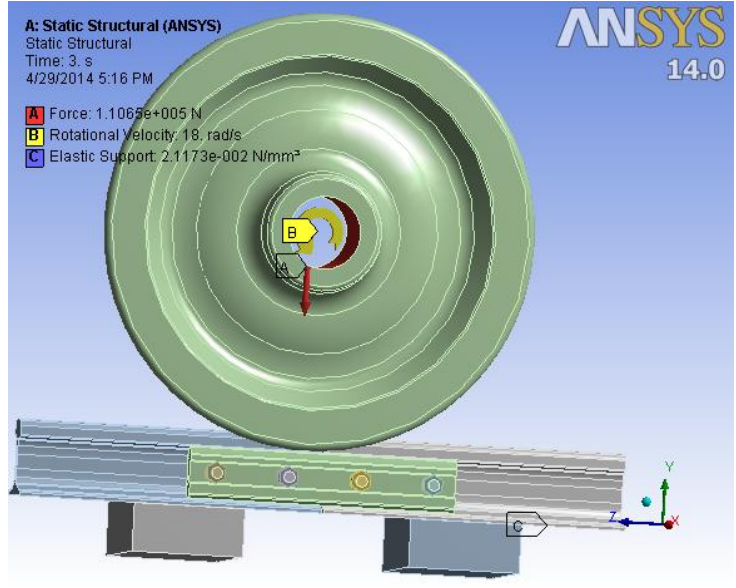

Fig.6 loading and boundary condition

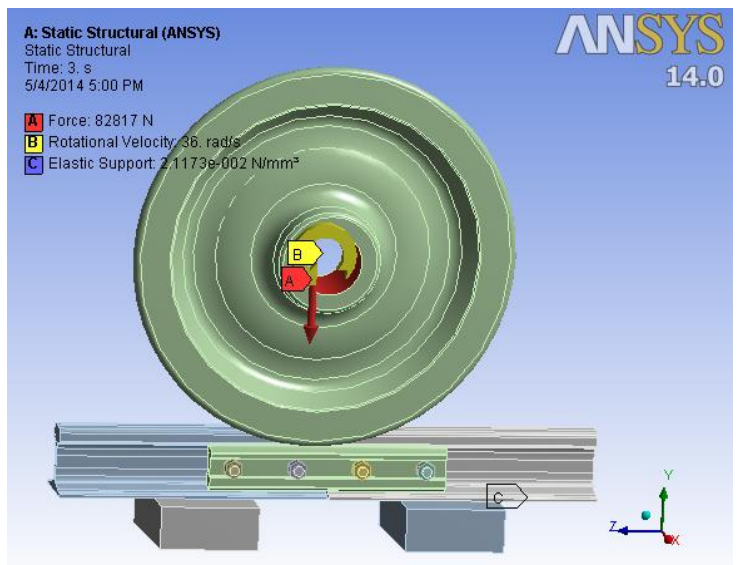

Fig.7 loading and boundary condition

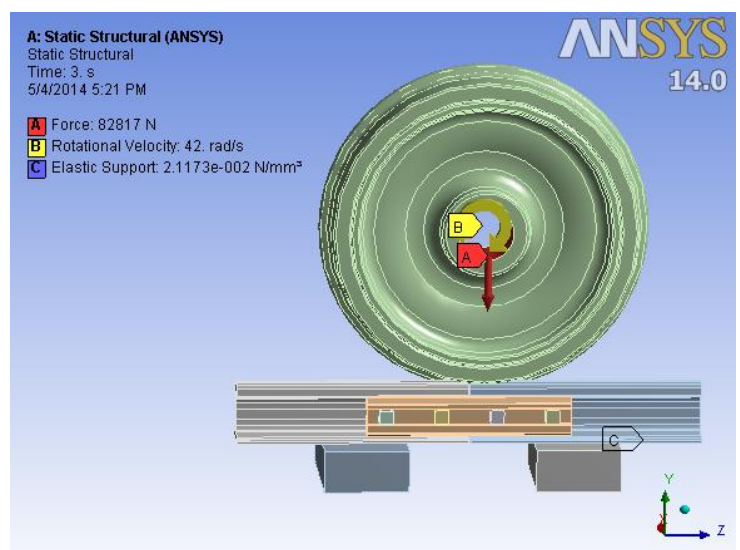

Fig.-8 loading and b zoundary condition

\begin{tabular}{|l|l|l|l|}
\hline $\begin{array}{l}\text { Stress in } \\
\text { (mpa) }\end{array}$ & $\begin{array}{l}\text { Second } \\
\text { class3-tier } \\
\text { sleeper } \\
\text { load }\end{array}$ & $\begin{array}{l}1^{\text {st }} \text { class a/c } \\
\text { load }\end{array}$ & $\begin{array}{l}\text { Diesel } \\
\text { locomotive } \\
\text { WDM3 engine } \\
\text { load }\end{array}$ \\
\hline $\begin{array}{l}\text { Von mises } \\
\text { stress }\end{array}$ & 344.5 & 394.31 & 520.12 \\
\hline $\begin{array}{l}\text { Maximum } \\
\text { shear stress }\end{array}$ & 194.32 & 222.29 & 292.9 \\
\hline
\end{tabular}

\section{RESULTS}

The von mises stresses, maximum shear stress and Equivalent elastic strain have been determined under the influence of axle load and train speed.

\subsection{Effect of Axle Load}

Under the condition of $\mathrm{Vo}=18 \mathrm{rad} / \mathrm{s}$ or $30 \mathrm{~km} / \mathrm{h}$, the effect of the $60 \%$ of the axle load or vertically downward load on the von mises stress, maximum shear stress and Equivalent elastic strain is shown in fig.

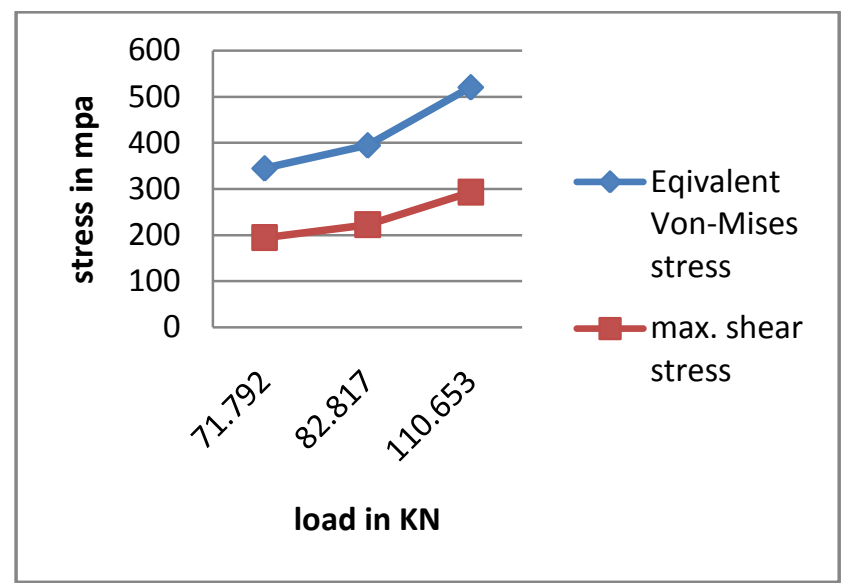

Fig.9 Equivalent Von-Mises Stress and Maximum Shear Stress Vs. Axle Load

\begin{tabular}{|l|l|l|l|}
\hline $\begin{array}{l}\text { Strain in } \\
(\mathrm{mm} / \mathrm{mm})\end{array}$ & $\begin{array}{l}\text { Second } \\
\text { class3-tier } \\
\text { sleeper load }\end{array}$ & $\begin{array}{l}\text { 1st class a/c } \\
\text { load }\end{array}$ & $\begin{array}{l}\text { Diesel } \\
\text { locomotive } \\
\text { WDM3 } \\
\text { engine load }\end{array}$ \\
\hline $\begin{array}{l}\text { Equivalent } \\
\text { elastic strain }\end{array}$ & 0.0016405 & 0.0018777 & 0.0024767 \\
\hline
\end{tabular}

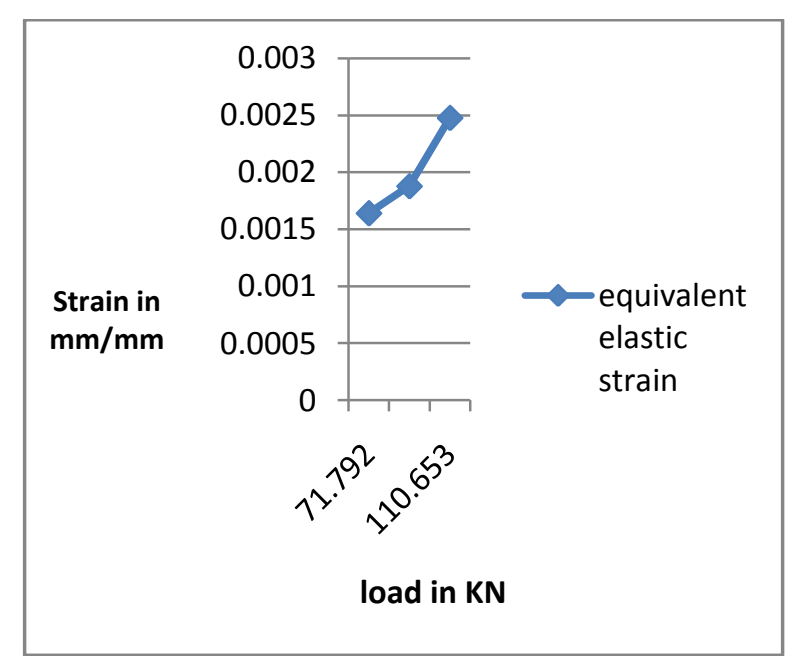

Fig.10 Equivalent Elastic Strain Vs. Axle Load

\subsection{Effect of Train Speed}

Under the condition of $\mathrm{P} 0=82.81 \mathrm{KN}$ the, influence of the train speed on the von mises stress, maximum shear stress and Equivalent elastic strain is shown in fig. 


\begin{tabular}{|l|l|l|l|}
\hline Stress in (mpa) & $18 \mathrm{rad} / \mathrm{s}$ & $36 \mathrm{rad} / \mathrm{s}$ & $42 \mathrm{rad} / \mathrm{s}$ \\
\hline $\begin{array}{l}\text { Von mises } \\
\text { stress }\end{array}$ & 394.31 & 455.87 & 486.21 \\
\hline $\begin{array}{l}\text { Maximum } \\
\text { shear stress }\end{array}$ & 222.29 & 259.38 & 277.48 \\
\hline
\end{tabular}

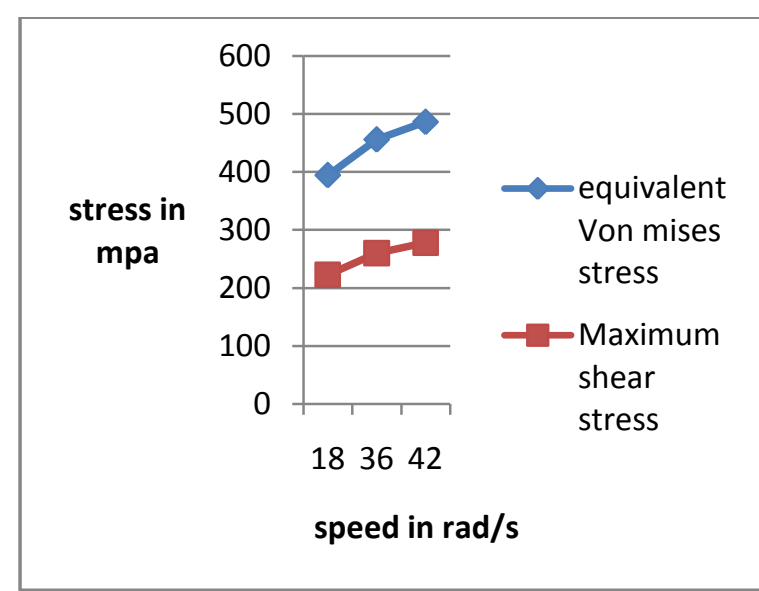

Fig.11 Equivalent Von-Mises Stress and Maximum Shear Stress Vs. Speed

\begin{tabular}{|l|l|l|l|}
\hline $\begin{array}{l}\text { Strain in } \\
(\mathrm{mm} / \mathrm{mm})\end{array}$ & $18 \mathrm{rad} / \mathrm{s}$ & $36 \mathrm{rad} / \mathrm{s}$ & $42 \mathrm{rad} / \mathrm{s}$ \\
\hline $\begin{array}{l}\text { Equivalent } \\
\text { elastic strain }\end{array}$ & 0.0018777 & 0.0021708 & 0.0023153 \\
\hline
\end{tabular}

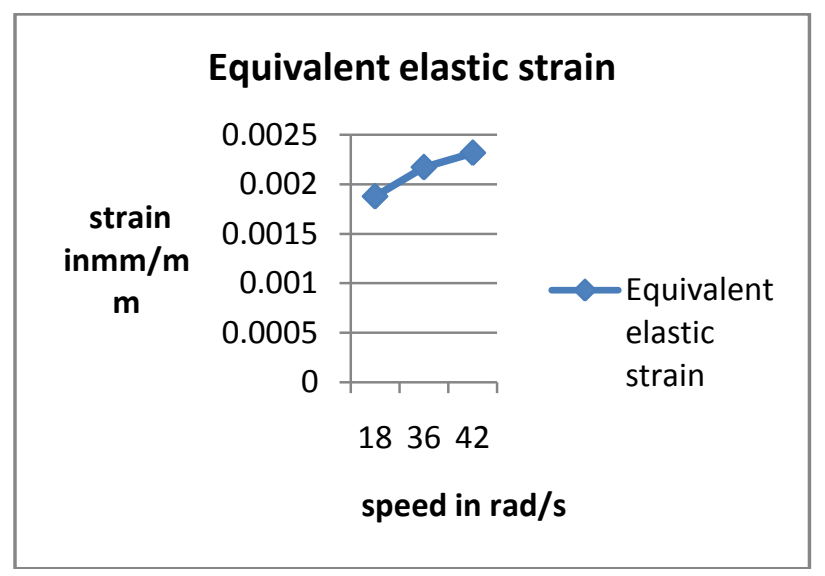

Fig.12 Equivalent Elastic Strain Vs. Speed

The influence of axle load and train speed on the von mises stresses, the maximum shear stress and the Equivalent elastic strain is plotted in figs. Figures indicate that the von mises stresses, the maximum shear stress and the Equivalent elastic strain are increases linearly with increasing axle load and the effect of train speed on above parameters is relatively weak.

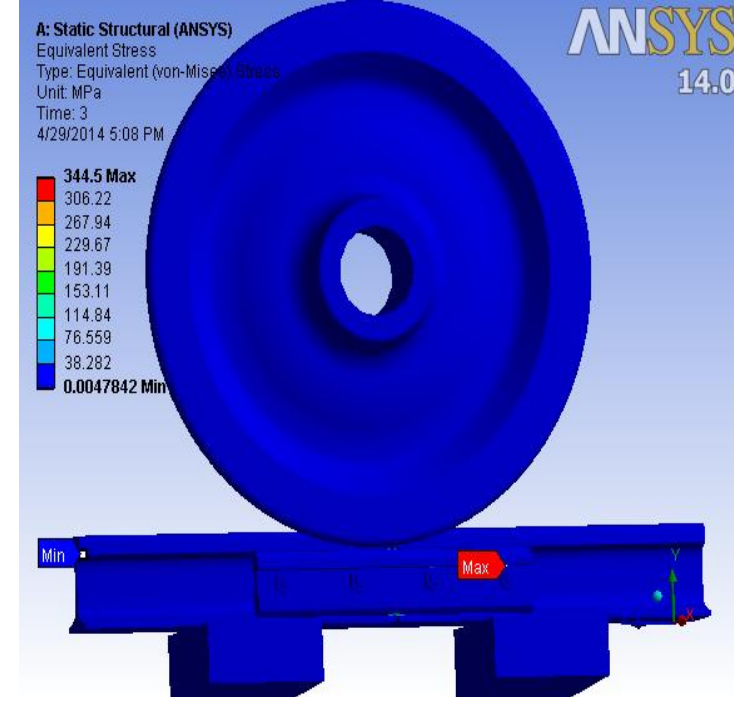

Fig.13Equivalent von-Mises stress in rail joint

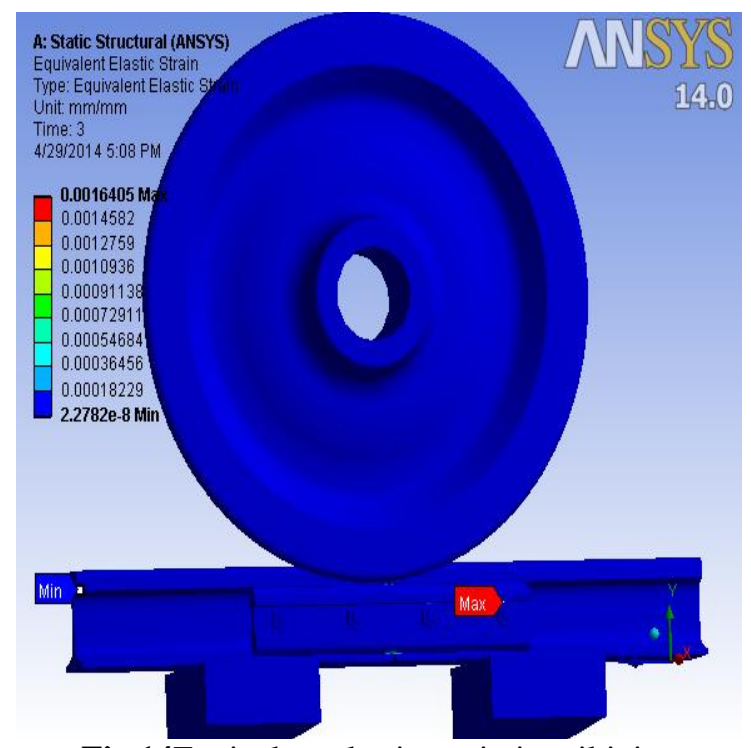

Fig.14Equivalent elastic strain in rail joint

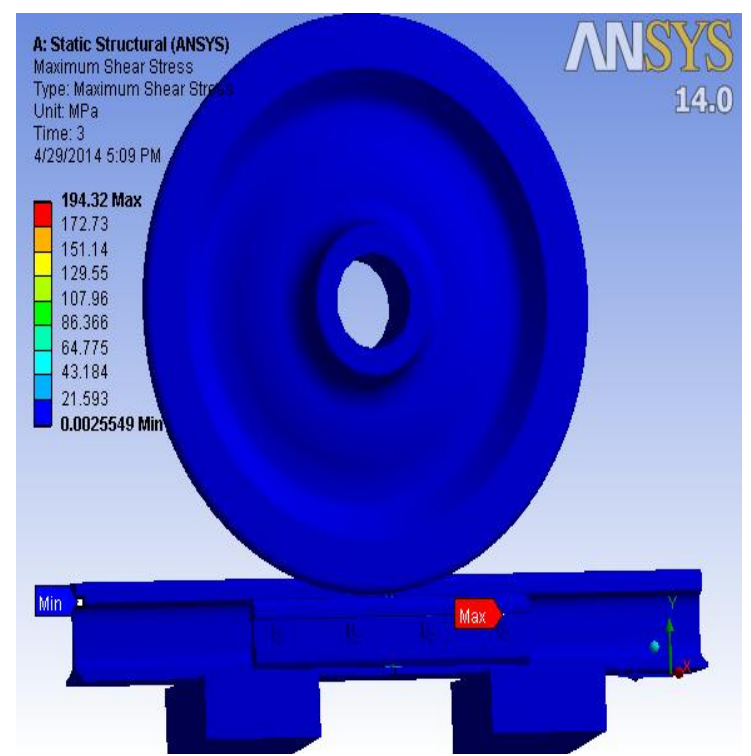

Fig.15 maximum shear stress in rail joint 


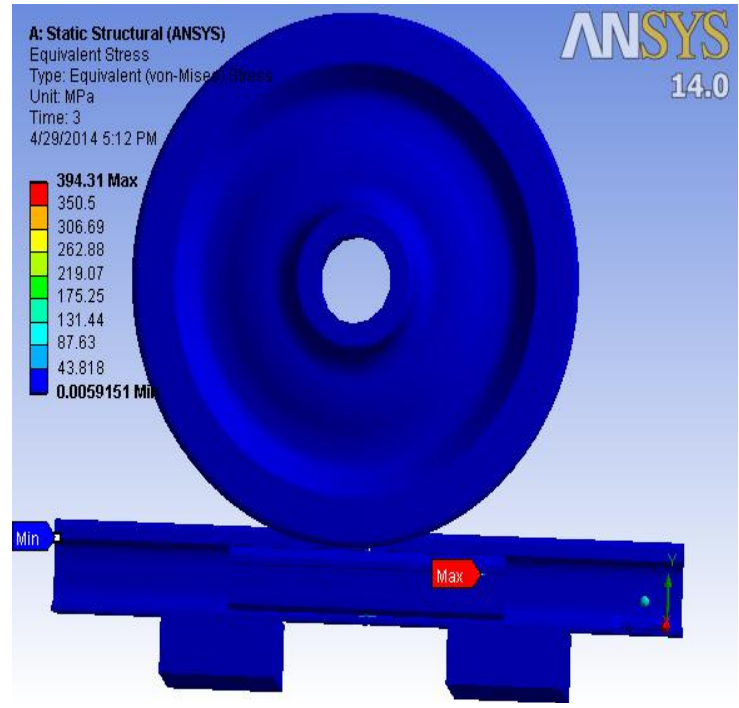

Fig.16Equivalent von-Mises stress in rail joint

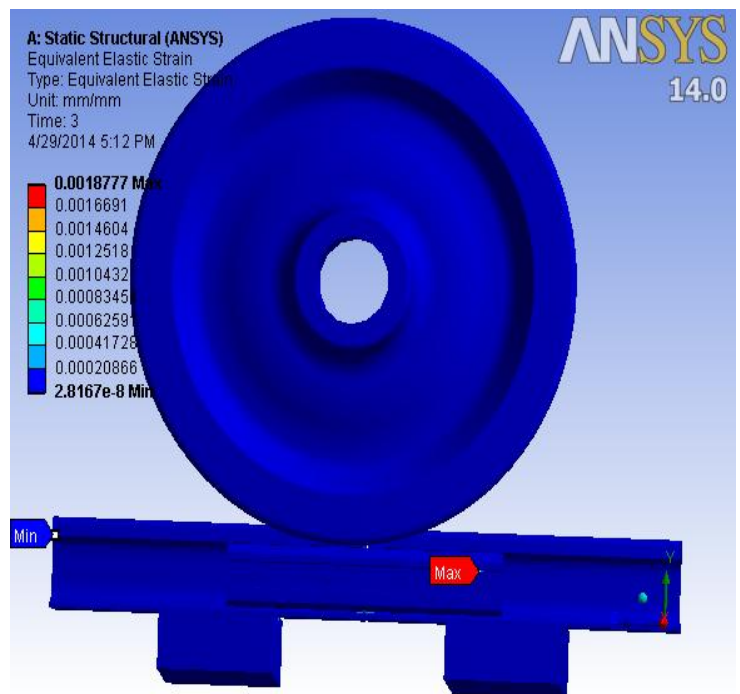

Fig.17Equivalent elastic strain in rail joint

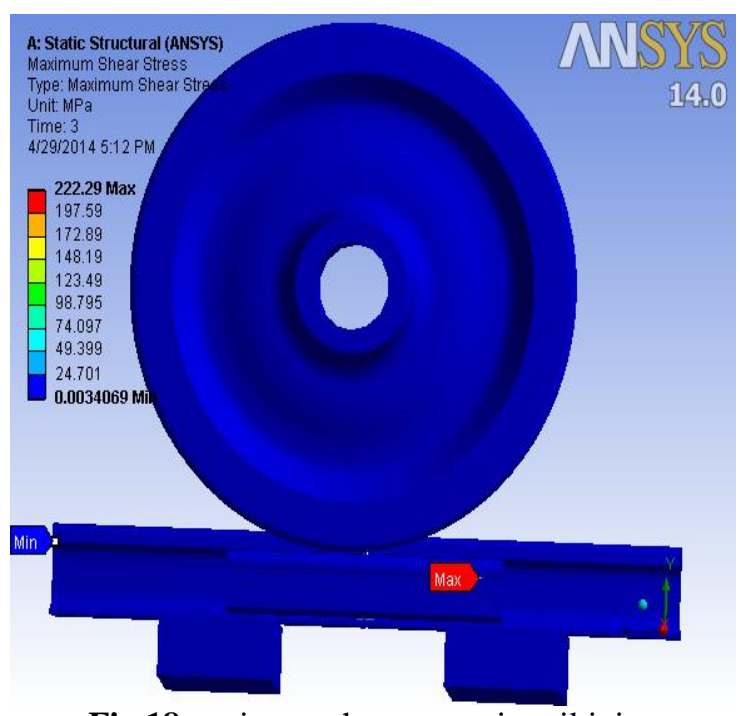

Fig.18maximum shear stress in rail joint

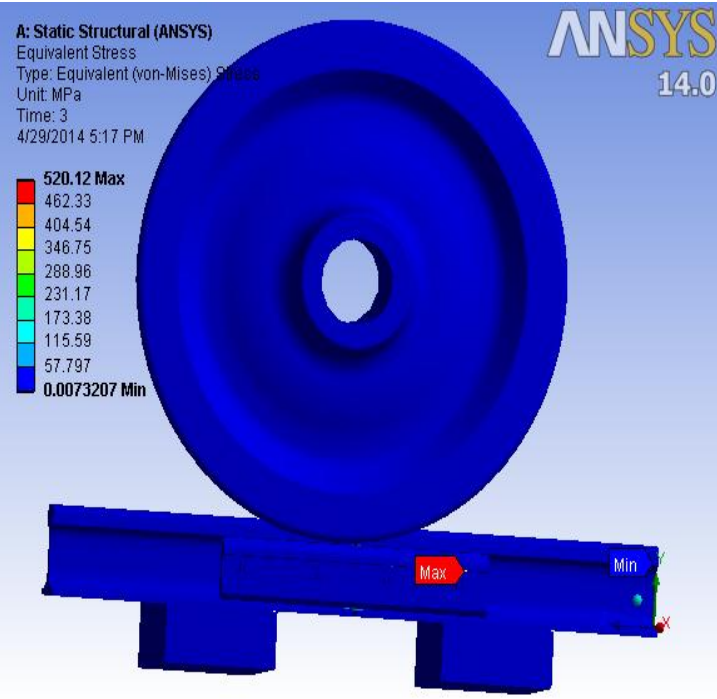

Fig.19Equivalent Von-Mises stress in rail joint

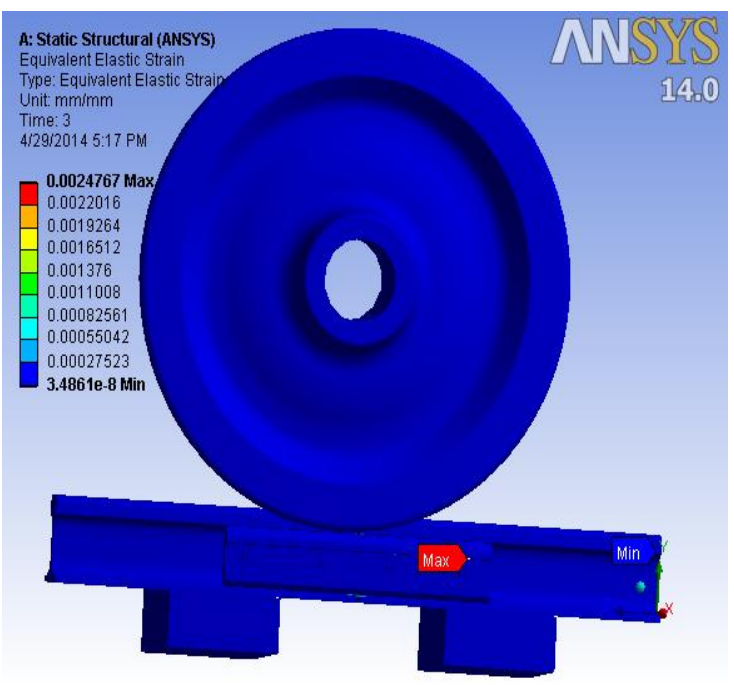

Fig.20Equivalent elastic strain in rail joint

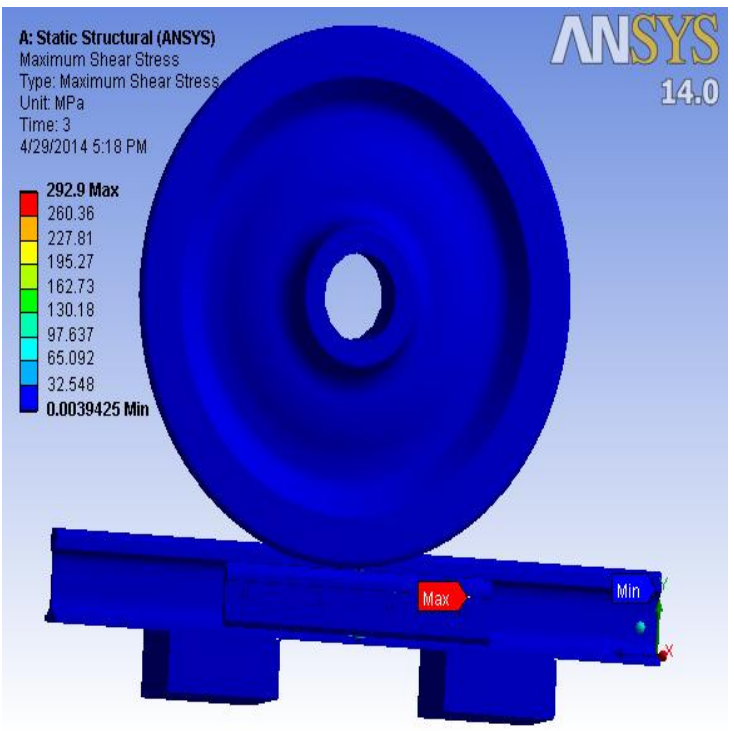

Fig.21maximum shear stress in rail joint 


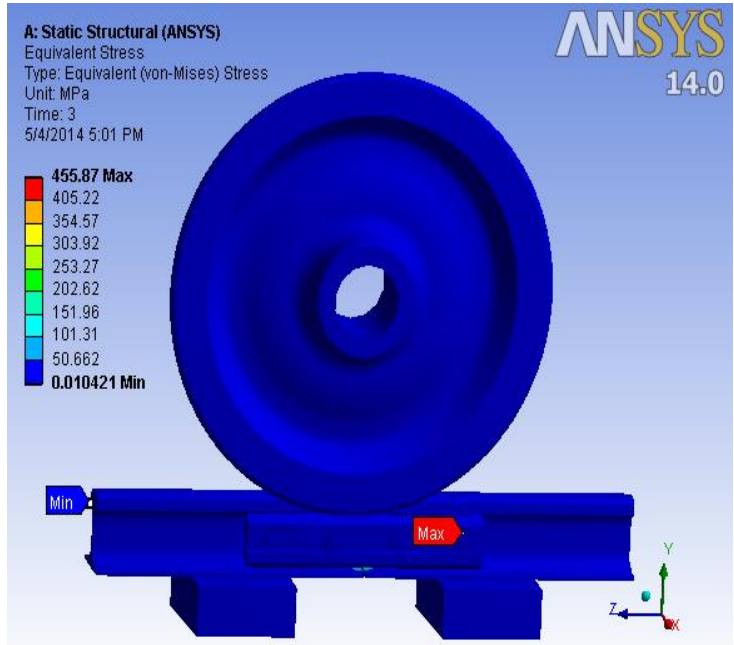

Fig.22Equivalent Von-Mises in rail joint

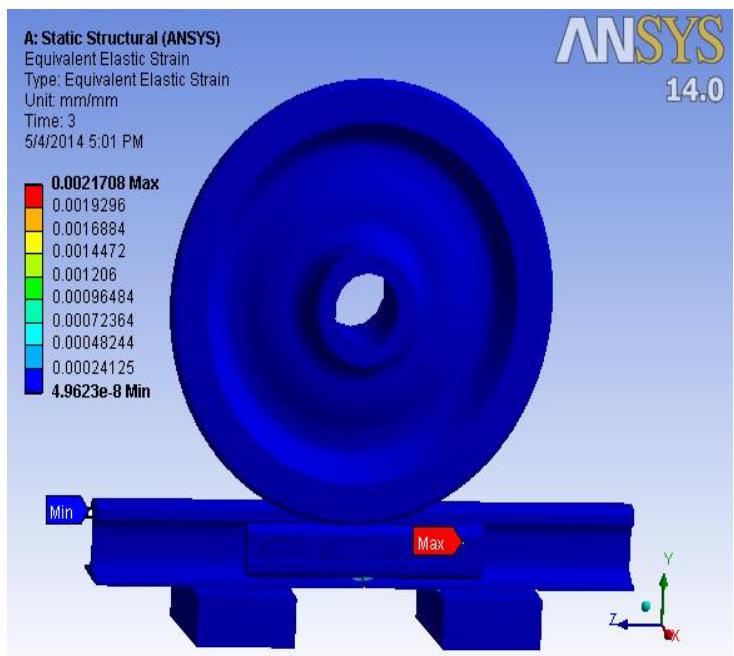

Fig.23Equivalent elastic strain in rail joint

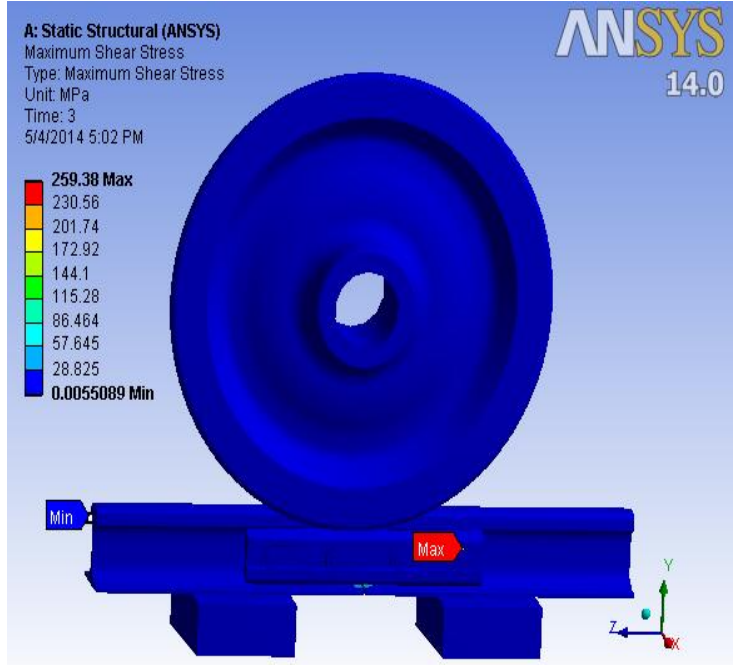

Fig.24maximum shear stress in rail joint

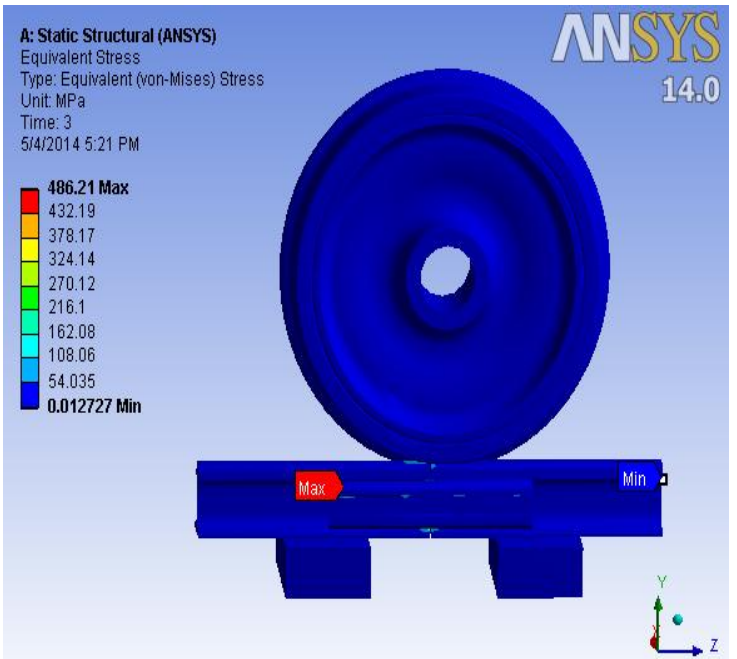

Fig.25Equivalent Von-Mises stress in rail joint

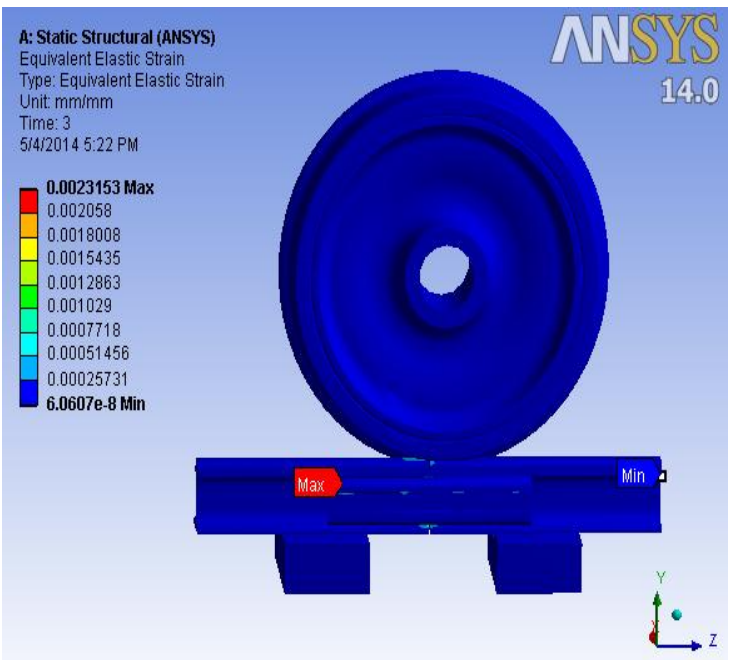

Fig.26Equivalent elastic strain in rail joint

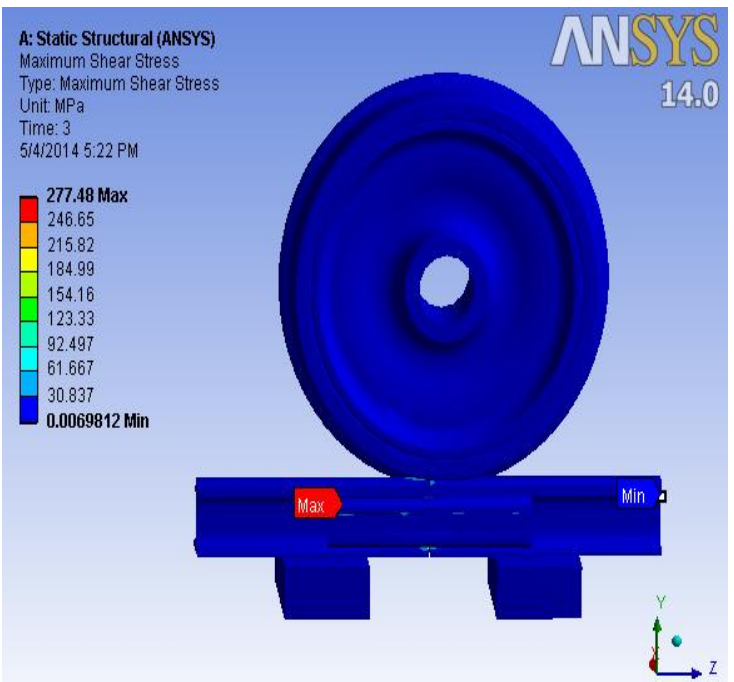

Fig.27maximum shear stress in rail joint 


\section{CONCLUSIONS}

A three-dimensional finite element model is used to analysis the wheel-rail contact impact at rail joint section of track. The finite element program ansys is used to model the contact analysis. This ANSYS is used to simulate the loading and boundary conditions of the rail and wheel contact for a stress analysis. The effects of axle load and train speed at rail joint are investigated in detail. The results from the present investigation are indicates that the axle load has a larger effect on the stresses and strain at the constant speed. The results also indicate that the effect of train speed is relatively weak than to the axle load.

\section{REFERENCES}

[1] Anon., AREMA Manual for Railway Engineering, Vol. 1, Track, American Railway Engineering and Maintenance-of-Way Association, (1999).

[2] B. Talamini, J. Gordon, and A.B. Perlman, "Finite Element Estimation of the Residual Stresses in Roller Straightened Rail," Proceedings of the 2004 ASME International Mechanical Engineering Congress (2004).D.Y. Jeong, "Engineering Analysis of the Impact Load at Rail Joints and Its Effect on Fatigue and Fracture of Joint Bars," US DOT/RITA Volpe Center, Cambridge, MA, DOT/FRA/ORD-04/06 (February 2004).

[3] D.Y. Jeong, Y.H. Tang, and O. Orringer, "Damage tolerance analysis of detail fractures in rail," Theoretical and Applied Fracture Mechanics 28, 109115 (1997).

[4] H.H. Jenkins, J.E. Stephenson, G.A. Clayton, G.W. Morland, and D. Lyon, "The effect of track and vehicle parameters on wheel/rail vertical dynamic forces," Railway Engineering Journal 3, 2-26 (1974).

[5] O. Orringer, Y.H. Tang, J.E. Gordon, D.Y. Jeong, J.M. Morris, and A.B. Perlman, "Crack Propagation Life of Detail Fractures in Rails," US DOT/RITA Volpe Center, Cambridge, MA, DOT/FRA/ORD88/13 (October 1988).

[6] R.A. Mayville and P.D. Hilton, "Fracture mechanics analysis of a rail-end bolt hole crack," Theoretical and Applied Fracture Mechanics 1, 51-60 (1984).

[7] R.A. Mayville, P.D. Hilton, and D.C. Pierce, "Investigation of Rail Bolt Hole Cracks," Final Report, DTRS-57-83-C-0078 (October 1987).

[8] R.A. Mayville and R.G. Stringfellow, "Numerical analysis of a railroad bolt hole fracture problem," Theoretical and Applied Fracture Mechanics 24, 1-12 (1995).

[9] R.S. Jensen, "Twelfth Progress Report of the RollingLoad Tests of Joint Bars," Proceedings of the 53rd Annual Convention of the American Railway Engineering Association, Vol. 55, 814-828 (1954).

[10] R.S. Jensen, "Fatigue tests of rail webs," American Railway Engineering Association Bulletin 51, 640647 (1950).

[11] Sunil Patel, Veerendra Kumar and Raji Nareliya, Fatigue analysis of rail joint using finite element method, IJRET (2013) 80-84.
[12] Zefeng wen, Xuesong Jin, Weihua Zhang, contactimpact stress analysis of rail joint region using the dynamic finite element method, wear 258 (2005) 1301-1309. 